\title{
The Effects of Gallium Additions on Microstructures and Thermal and Mechanical Properties of Sn-9Zn Solder Alloys
}

\author{
Kang I. Chen, ${ }^{1}$ Shou C. Cheng, ${ }^{1}$ Chin H. Cheng, ${ }^{2}$ Sean Wu, \\ Yeu-L. Jiang, ${ }^{3}$ and Tsung-C. Cheng ${ }^{4}$ \\ ${ }^{1}$ Department of Electronics Engineering and Computer Science, Tung Fang Design Institute, No. 110, Dong Fang Road, \\ Hunei, Kaohsiung 82941, Taiwan \\ ${ }^{2}$ Department of Aeronautics and Astronautics, Research Center for Energy Technology and Strategy, National Cheng Kung University, \\ Tainan 70101, Taiwan \\ ${ }^{3}$ Department of Electrical Engineering, National Chung Hsing University, Taichung 40227, Taiwan \\ ${ }^{4}$ Department of Mechanical Engineering, National Kaohsiung University of Applied Sciences, Kaohsiung 80778, Taiwan
}

Correspondence should be addressed to Kang I. Chen; kangichen@mail.tf.edu.tw

Received 19 September 2013; Revised 10 December 2013; Accepted 12 December 2013; Published 22 January 2014

Academic Editor: Tao Zhang

Copyright (C) 2014 Kang I. Chen et al. This is an open access article distributed under the Creative Commons Attribution License, which permits unrestricted use, distribution, and reproduction in any medium, provided the original work is properly cited.

\begin{abstract}
The effects of gallium additions on microstructures and thermal and mechanical properties of the Sn-9Zn solder alloys are investigated in this study. The results show that the melting temperature of the alloys decreases with the increase in the Ga concentration, while the pasty ranges of the alloys are simultaneously enlarged. By adding a $0.25-0.5$ wt.\% Ga element, the Snmatrix region is slightly increased and the Zn-rich phase becomes slightly coarser; however, the overall microstructure is still very similar to that of the Sn-9Zn alloy. It is found that, when the Ga concentration is less than $0.50 \mathrm{wt} . \%$, the ultimate tensile strength and elongation are maintained at the same values. The addition of a $0.25-0.50 \mathrm{wt}$.\% Ga to the Sn-9Zn alloy also leads to small cup and cone fracture surfaces which exhibit near-complete ductile fracturing. With the addition being increased to $0.75 \mathrm{wt} . \%$, larger cup and cone fractures are observed. The $1.00 \mathrm{wt} \% \mathrm{Ga}$ alloy has lower strength and ductility due to the coarser and nonuniform microstructures. However, the fracture surfaces of the $1.00 \mathrm{wt} . \% \mathrm{Ga}$ alloy show partial cleavage and a partially dimpled fracture.
\end{abstract}

\section{Introduction}

Conventional $\mathrm{Sn}-\mathrm{Pb}$ solders have commonly been used as the interconnection materials for soldering electronic components and devices. However, the use of $\mathrm{Pb}$ is restricted due to health and environmental issues. On the other hand, an alloy of $\mathrm{Sn}-\mathrm{Ag}-\mathrm{Cu}$ has been recognized as a potential leadfree solder even though $\mathrm{Sn}-\mathrm{Ag}$ alloy systems have higher melting points (say, 216 to $221^{\circ} \mathrm{C}$ ), as compared to an eutectic $\mathrm{Sn}-\mathrm{Pb}$ alloy $[1,2]$. A high melting point is accompanied by high soldering temperatures, which may give rise to substrate instability problems.

Recently, the Sn-9Zn alloy system has received increased interest since it features low cost, great mechanical properties, and a low eutectic temperature $\left(198^{\circ} \mathrm{C}\right)$, close to that of the $\mathrm{Sn}-\mathrm{Pb}$ alloy $[2,3]$. The eutectic structure of the $\mathrm{Sn}-9 \mathrm{Zn}$ alloy system consists of two phases: a body centered tetragonal Sn matrix phase and a secondary phase of hexagonal $\mathrm{Zn}$ containing less than 0.039 at.\% Sn in solid solution $[3,4]$. However, the tendency of oxidation and poor wetting ability of this alloy system limits its application $[5,6]$. In recent years, to overcome the shortfalls in the Sn-9Zn alloy, some authors have tried to add a third element, such as In [7], Ga [8], Bi [9-13], Al [14-18], Ag [19-22], $\mathrm{Cr}$ [23], $\mathrm{Cu}$ [24], and $\mathrm{Ce} / \mathrm{La}$ [25-27], to the Sn-Zn binary system to improve the melting temperature, wettability, oxidation resistance, corrosion, and mechanical properties of the alloy. For example, McCormack and Jin [7] found that, as the element In is added to the SnZn binary system, the wetting characteristics of the alloy can be improved and the melting temperature can be appreciably lowered. Kim et al. [9] reported that, with an addition of the element $\mathrm{Bi}$, the melting point is decreased from 198.4 
to $186.1^{\circ} \mathrm{C}$. Lin and Liu $[17,18]$ added the $\mathrm{Al}$ element into the $\mathrm{Sn}-\mathrm{Zn}$ alloy and showed that element $\mathrm{Al}$ can improve wetting properties and oxidation resistance. It has also been found that Sn-Zn-Ag solders [19] have good wettability on $\mathrm{Cu}$ substrates. Meanwhile, Wu et al. $[25,26]$ found that, by adding $\mathrm{Ce} / \mathrm{La}$ into the $\mathrm{Sn}-\mathrm{Zn}$ system, one could improve wettability, creep strength, and tensile strength.

The melting point of gallium is $29.78^{\circ} \mathrm{C}$ [29]. It has high thermal and electrical conductivity and reactivity with copper forming amalgams. In addition, its inherent characteristic of wetting most metals and oxides without the use of flux can be a very attractive property for microelectronic devices [30]. According to the Ga-Zn [31] and Ga- Sn [32], binary-phase diagrams, Ga may form solid solutions with $\mathrm{Sn}$ and $\mathrm{Zn}$. There is a great need for a lead-free solder with the same melting point as the near-eutectic $63 \mathrm{Sn}-37 \mathrm{~Pb}$ alloy.

Based on the existing information discussed above, most of the previous reports were focused on improving the melting temperature and wettability of the $\mathrm{Sn}-\mathrm{Zn}$ alloy, and very few studies have been conducted to study the improvement in other thermal and mechanical properties. Therefore, the objective of this study is aimed at investigating the effects of adding gallium to the microstructures and the thermal and mechanical properties of a Sn-9Zn lead-free solder.

\section{Materials and Experimental Methods}

A series of alloys of tin, zinc, and gallium are prepared from pure elements (greater than $99.99 \%$ pure). The Ga content in the $\mathrm{Sn}-9 \mathrm{Zn}-x \mathrm{Ga}$ solders, represented by $x$, is varied between 0 and 1.0 wt.\%. Table 1 shows the chemical composition of the solder alloys. The constituent elements have been melted in a quartz tube with an inside diameter of $8 \mathrm{~mm}$ under an argon atmosphere. The molten alloys (in the quartz tube) are homogenized at $800^{\circ} \mathrm{C}$ for 3 hours, the furnace cooled to $250^{\circ} \mathrm{C}$, and then water $\left(25^{\circ} \mathrm{C}\right)$ quenched, while the quartz tube jacket is still. The solder rods are then machined into tensile specimens with a $16 \mathrm{~mm}$ gauge length and $4 \mathrm{~mm}$ gauge diameter. Tensile tests are then performed at room temperature at a strain rate of $0.9 \mathrm{~mm} / \mathrm{min}$. The melting temperatures of the solder alloys are measured with differential scanning calorimetry (DSC). In the DSC analysis, a piece of solder about $10 \mathrm{mg}$ is placed into an $\mathrm{Al}$ cell. For collecting the data of melting properties, the sample is initially scanned from $25^{\circ} \mathrm{C}$ to $300^{\circ} \mathrm{C}$ at a rate of $0.5^{\circ} \mathrm{C} / \mathrm{min}$ under an argon atmosphere, then a phase identification of the various solders is carried out by using an X-ray diffractometer operated at $30 \mathrm{kV}$, and the $\mathrm{Cu}-\mathrm{K} \alpha$ radiation is used at diffraction angles $(2 \theta)$ from $35^{\circ}$ to $47^{\circ}$ with a scanning speed of $1^{\circ} / \mathrm{min}$. The as-cast solders are sectioned, metallographically polished, and examined by using a scanning electron microscope (SEM). The composition of the precipitates and phases in the solidified solders are analyzed with an energy dispersive spectrometer (EDS) and a wavelength dispersive spectrometer (WDS).
TABLE 1: The chemical composition of the solder alloys.

\begin{tabular}{lccc}
\hline The solder alloys & Zn (wt.\%) & Ga (wt.\%) & Sn (wt.\%) \\
\hline Sn-9Zn & 9 & 0 & Balance \\
Sn-9Zn-0.25Ga & 9 & 0.25 & Balance \\
Sn-9Zn-0.50Ga & 9 & 0.50 & Balance \\
Sn-9Zn-0.75Ga & 9 & 0.75 & Balance \\
Sn-9Zn-1.00Ga & 9 & 1.00 & Balance \\
\hline
\end{tabular}

\section{Results and Discussion}

3.1. The Thermal Properties of the Sn-Zn-xGa Alloys. Figure 1 shows the DSC curves of the Sn-Zn eutectic alloy and a series of $\mathrm{Sn}-9 \mathrm{Zn}-x \mathrm{Ga}$ alloys upon heating at a scanning rate of $0.5^{\circ} \mathrm{C} / \mathrm{min}$. The melting temperature of the alloys is decreased with an increase in the $\mathrm{Ga}$ concentration, but the pasty ranges of the alloys are simultaneously enlarged. A promising solder alloy should have a lower melting temperature and a narrow pasty temperature zone. As expected, the melting temperature for the $\mathrm{Sn}-9 \mathrm{Zn}-x \mathrm{Ga}$ alloy is decreased by increasing the $\mathrm{Ga}$ content. The melting temperature of $\mathrm{Sn}-9 \mathrm{Zn}, T_{m}$, at its endothermic peak is $199.8^{\circ} \mathrm{C}$. An addition of $0.5 \mathrm{wt} . \%$ $\mathrm{Ga}$ reduces the value of $T_{m}$ to $198.8^{\circ} \mathrm{C}$, and an addition of 1.0 wt. $\% \mathrm{Ga}$ further reduces the value of $T_{m}$ to $196.8^{\circ} \mathrm{C}$. In the meantime, the addition of a small amount of Ga slightly expands the temperature interval of the pasty range, which is defined by the difference between the liquidus and solidus temperatures, $T_{\text {end }}-T_{\text {onset }}$, as shown in Figure 2. In this figure, it is observed that an addition of $0.25 \mathrm{wt} . \% \mathrm{Ga}$ causes the measured pasty range of $\mathrm{Sn}-9 \mathrm{Zn}$ to change from 2.0 to $3.4^{\circ} \mathrm{C}$, while an addition of an amount of $1.0 \mathrm{wt} . \% \mathrm{Ga}$ increases the pasty range to $5.7^{\circ} \mathrm{C}$, which is still lower than that of $\mathrm{Sn}-\mathrm{Pb}$ eutectic [12], $11.5^{\circ} \mathrm{C}$. A higher liquidus or melting temperature means a higher processing temperature is needed.

The comparison of solidus temperature $\left(T_{\text {onset }}\right)$, liquidus temperature $\left(T_{\text {end }}\right)$, pasty ranges $\left(T_{\text {end }}-T_{\text {onset }}\right)$, melting temperature $\left(T_{m}\right), A / m$, and $\Delta H$ among various solder alloys measured by the DSC is provided in Table 2. Again, it is seen that an increase in the amount of Ga lowers the melting temperature of the solder. According to the Ga-Sn binary phase diagram, it is known that Ga may form solid solutions with $\mathrm{Sn}$. The maximum solubility of $\mathrm{Ga}$ in $\mathrm{Sn}$ is 6.4 at.\% at $20.7^{\circ} \mathrm{C}$ [32]. The eutectic temperature of Sn-Ga eutectic alloy is also $20.5^{\circ} \mathrm{C}$, which could lower the melting point of the Sn$9 \mathrm{Zn}-x \mathrm{Ga}$ alloys. In addition, the eutectic temperature of the $\mathrm{Zn}$-Ga eutectic alloy is $24.7^{\circ} \mathrm{C}$, and the maximum solubility of $\mathrm{Ga}$ in $\mathrm{Zn}$ is about 3.87 at.\% at $24.7^{\circ} \mathrm{C}$ [31]. Therefore, all melting temperatures of the $\mathrm{Sn}-9 \mathrm{Zn}-x \mathrm{Ga}$ solder alloys are lower than the eutectic temperatures of the Sn-9Zn eutectic alloy.

The heat of fusion $(\Delta H)$ can be determined by [33]

$$
\Delta H=k \frac{A}{m},
$$

where $k$ is a constant with a value of 2.64 for pure tin [33], $m$ is the mass of the sample, and $A$ is the area under the endothermic peak. From Table $2, A / m$ is determined as 


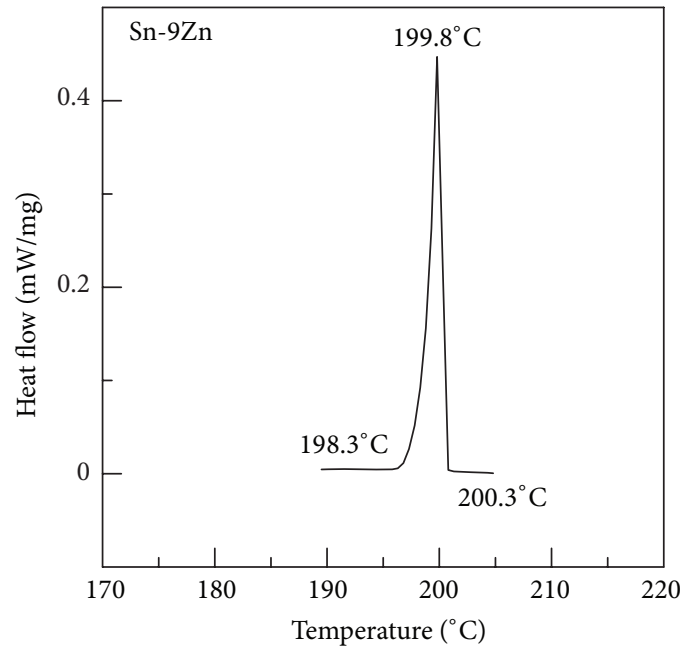

(a)

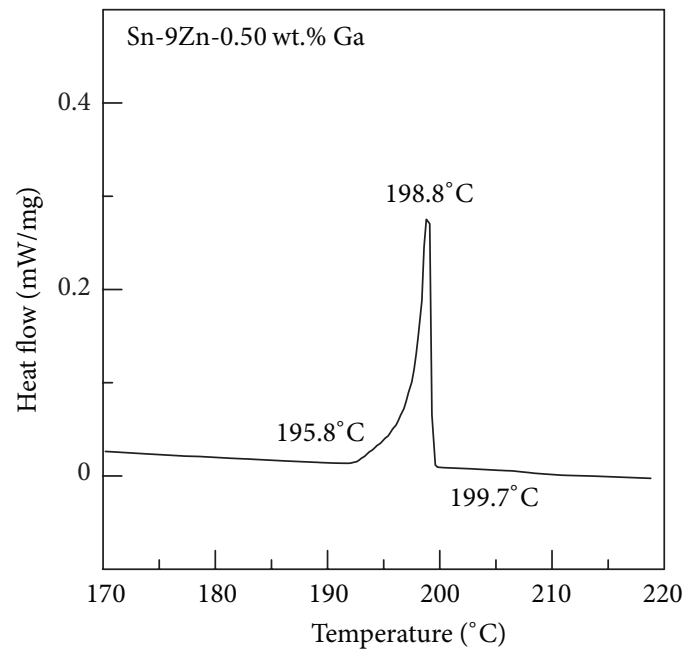

(c)

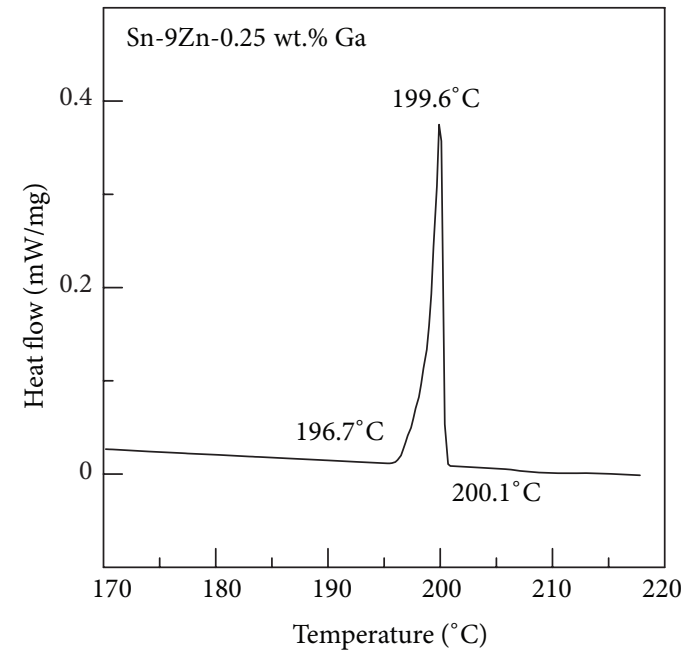

(b)

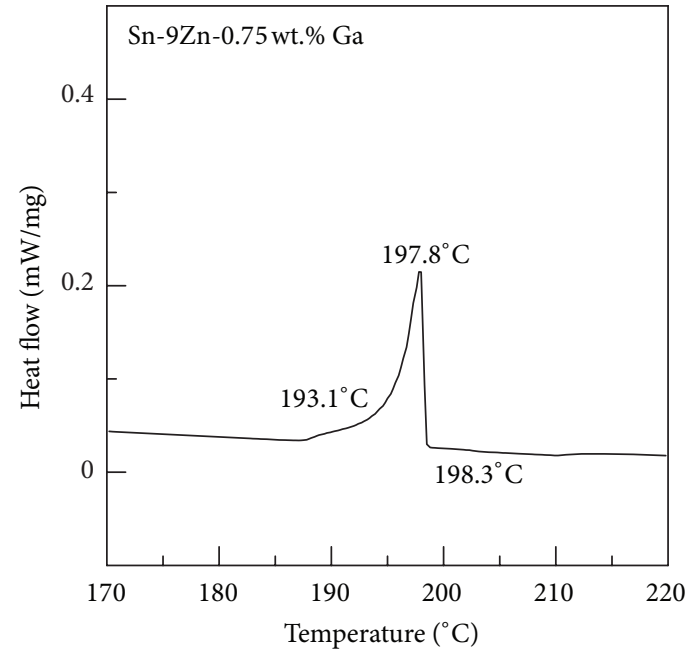

(d)

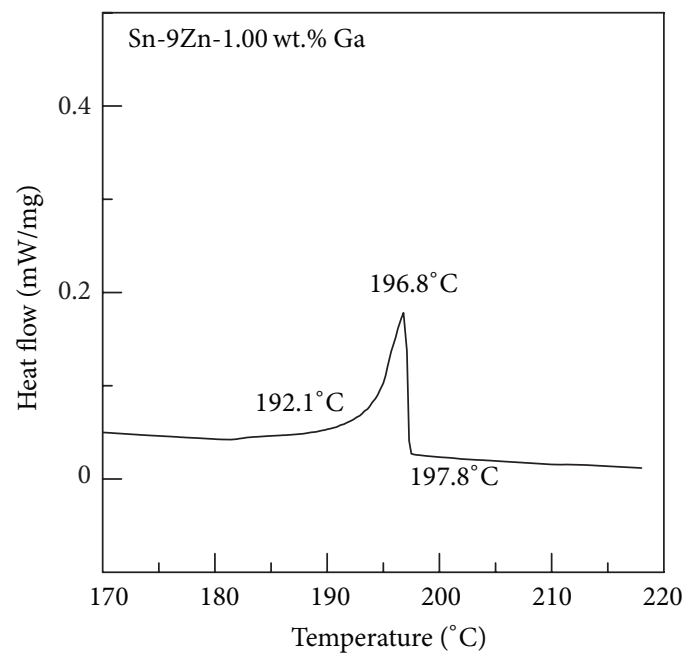

(e)

Figure 1: The DSC curves of the Sn-9Zn- $x$ Ga solder alloys containing (a) 0 wt.\% Ga, (b) 0.25 wt.\% Ga, (c) 0.50 wt.\% Ga, (d) 0.75 wt.\% Ga, and (e) $1.00 \mathrm{wt} . \% \mathrm{Ga}$ upon heating at a scanning rate of $0.5^{\circ} \mathrm{C} / \mathrm{min}$. 
TABLE 2: The comparison of solidus temperature $\left(T_{\text {onset }}\right)$, liquidus temperature $\left(T_{\text {end }}\right)$, pasty ranges $\left(T_{\text {end }}-T_{\text {onset }}\right)$, melting temperature $\left(T_{m}\right)$, $A / m$, and $\Delta H$ among various solder alloys.

\begin{tabular}{lcccccc}
\hline Solder alloys & $T_{\text {onset }}\left({ }^{\circ} \mathrm{C}\right)$ & $T_{\text {end }}\left({ }^{\circ} \mathrm{C}\right)$ & $T_{\text {end }}-T_{\text {onset }}\left({ }^{\circ} \mathrm{C}\right)$ & $T_{m}\left({ }^{\circ} \mathrm{C}\right)$ & $A / m(\mathrm{~J} / \mathrm{g})$ & $\Delta H(\mathrm{~J} / \mathrm{g})$ \\
\hline Sn-9Zn & 198.3 & 200.3 & +2.0 & 199.8 & 189.2 & 185.3 \\
Sn-9Zn-0.25Ga & 196.7 & 200.1 & +3.4 & +3.9 & 198.8 & 67.6 \\
Sn-9Zn-0.50Ga & 195.8 & 199.7 & +5.2 & 197.8 & 62.4 & 59.8 \\
Sn-9Zn-0.75Ga & 193.1 & 198.3 & +5.7 & 196.8 & 57.2 \\
Sn-9Zn-1.00Ga & 192.1 & 197.8 & & & 164.7 \\
\hline
\end{tabular}

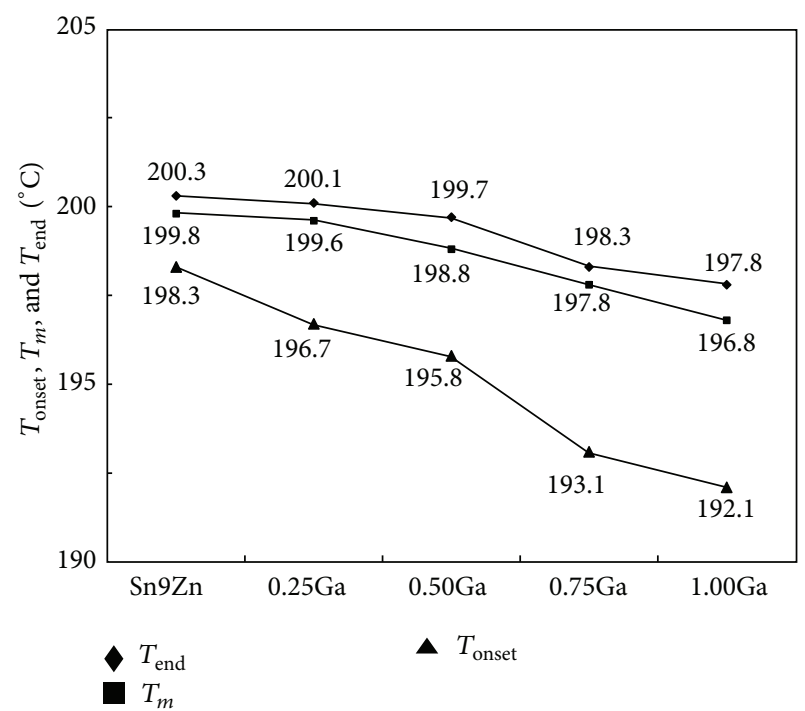

FIGURE 2: The solidus temperature $\left(T_{\text {onset }}\right)$, melting temperature $\left(T_{m}\right)$, and liquidus temperature $\left(T_{\text {end }}\right)$ of various solder alloys.

$70.2,67.6,62.4,59.8$, and $57.2 \mathrm{~J} / \mathrm{g}$ for the Sn-9Zn, Sn-9Zn0.25Ga, Sn-9Zn-0.5Ga, Sn-9Zn-0.75Ga, and Sn-9Zn-1.0Ga alloys, respectively. Consequently, the values of $\Delta H$ obtained are 185.3, 178.5, 164.7, 157.8, and $151.0 \mathrm{~J} / \mathrm{g}$ for the Sn-9Zn, Sn9Zn-0.25Ga, Sn-9Zn-0.5Ga, Sn-9Zn-0.75Ga, and Sn-9Zn$1.0 \mathrm{Ga}$ alloys, respectively, showing that it is necessary for energy to be consumed to melt the $\mathrm{Sn}-9 \mathrm{Zn}-x \mathrm{Ga}$ alloys.

3.2. X-Ray Diffractometry Analysis. The X-ray diffractometry (XRD) patterns of the Sn-9Zn, Sn-9Zn-0.25Ga, Sn-9Zn0.5Ga, Sn-9Zn-0.75Ga, and Sn-9Zn-1.0Ga alloys are shown in Figure 3. The XRD analysis of the $\mathrm{Sn}-9 \mathrm{Zn}$ alloy displays the phases of the eutectic structure. The Bragg peaks corresponding to $\operatorname{Sn}(211), \operatorname{Sn}(220), \mathrm{Zn}(101), \mathrm{Zn}(100)$, and $\mathrm{Zn}(002)$ are observed in the eutectic Sn-9Zn alloy. The Ga-Sn phase diagram [31] shows that Sn exhibits a maximum solubility of 6.4 at.\% Ga. Meanwhile, the Ga-Zn phase diagram [31] shows that a hexagonal $(\mathrm{Zn})$ solid solution possesses a maximum solubility of 2.36 at. $\% \mathrm{Ga}$ at $260^{\circ} \mathrm{C}$. The $\mathrm{Ga}-\mathrm{Sn}$ and $\mathrm{Ga}-\mathrm{Zn}$ binary phase diagrams indicate that $\mathrm{Ga}$ may form a solid solution with $\mathrm{Sn}$ and $\mathrm{Zn}$. Thus, most of the Ga was dissolved in the Sn-rich and Zn-rich phases. The Sn-Zn exhibits a binary eutectic behavior with no intermetallic compounds and a limited solubility of the two elements in each phase.

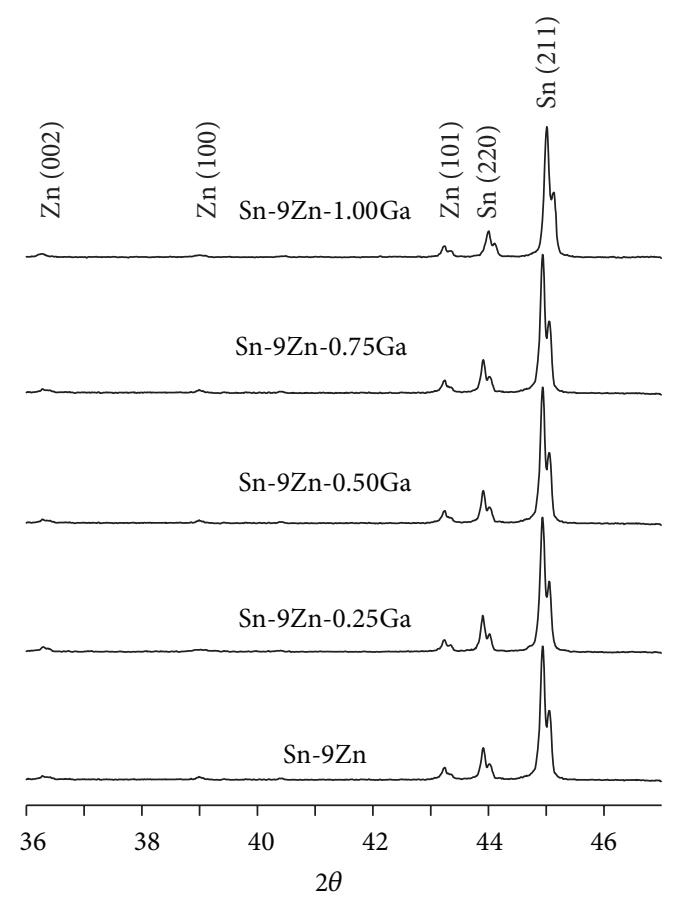

Figure 3: The XRD patterns of the Sn-9Zn, Sn-9Zn-0.25Ga, Sn9Zn-0.50Ga, Sn-9Zn-0.75Ga, and Sn-9Zn-1.00Ga solder alloys.

The results shown in this figure imply that the Sn-9Zn0.25Ga, Sn-9Zn-0.5Ga, Sn-9Zn-0.75Ga, and Sn-9Zn-1.0Ga alloys only form $\mathrm{Sn}$-matrixes and $\mathrm{Zn}$-rich phases.

When the gallium content is increased, the XRD peaks of the $\operatorname{Sn}(211)$ phase shift toward the higher-angle regime, from $44.94^{\circ}$ for $\mathrm{Sn}-9 \mathrm{Zn}$ to $45.01^{\circ}$ for $\mathrm{Sn}-9 \mathrm{Zn}-1.0 \mathrm{Ga}$, while the $\mathrm{Zn}(101)$ phase peak remains the same. Tin has the largest atomic radius $(0.3022 \mathrm{~nm})$; gallium has the smallest $(0.2484 \mathrm{~nm})$; and zinc has an atomic radius $(0.2664 \mathrm{~nm})$ between that of tin and gallium [29]. Therefore, when gallium atoms are dissolved in a $\mathrm{Sn}$-rich phase, it seems reasonable that the lattice parameter of the Sn-rich phase is decreased.

3.3. Microstructures. The microstructures of the Sn-9Zn$x \mathrm{Ga}$ alloys are shown in Figure 4 . The microstructure of the Sn-9Zn alloy is displayed in Figure 4(a). In this figure, the light contrasted areas indicate the Sn-rich phase $(\beta$ $\mathrm{Sn})$, and the darker needle-like areas represent the $\mathrm{Zn}$ rich phase. The cooling reaction at $250^{\circ} \mathrm{C}$ is $\mathrm{L}$ (liquid) $\rightarrow$ eutectic $(\mathrm{Sn}-\mathrm{Zn})$. As illustrated in Figures 4(b) and 4(c), 


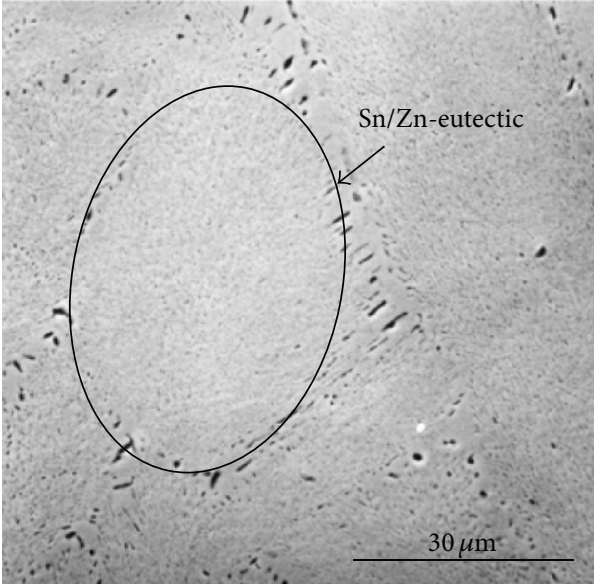

(a)

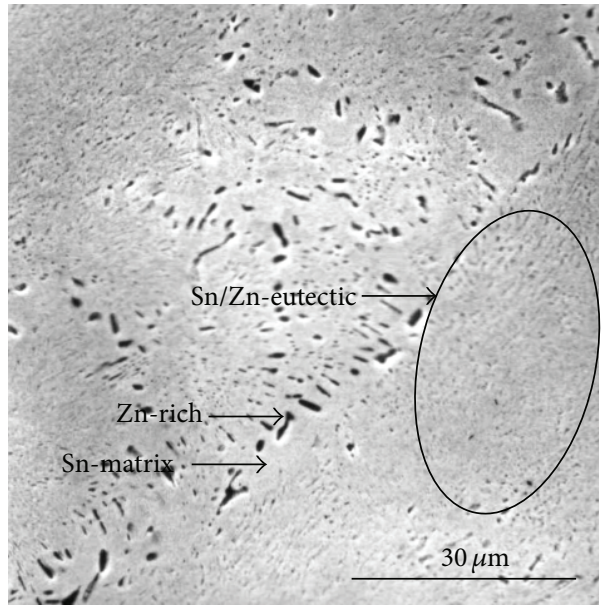

(c)

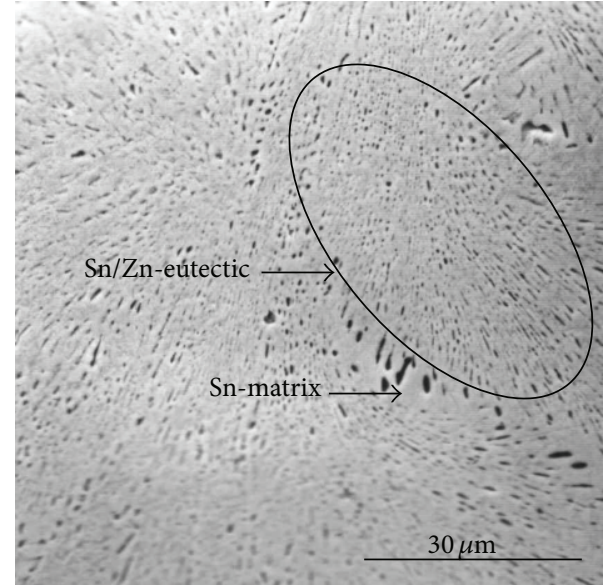

(b)

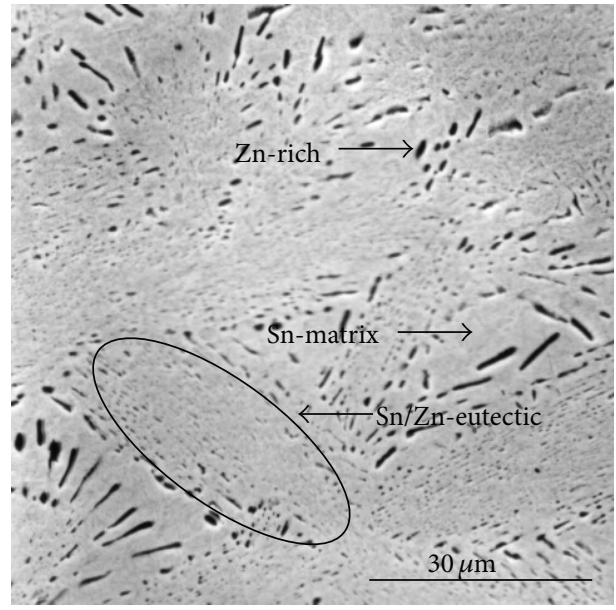

(d)

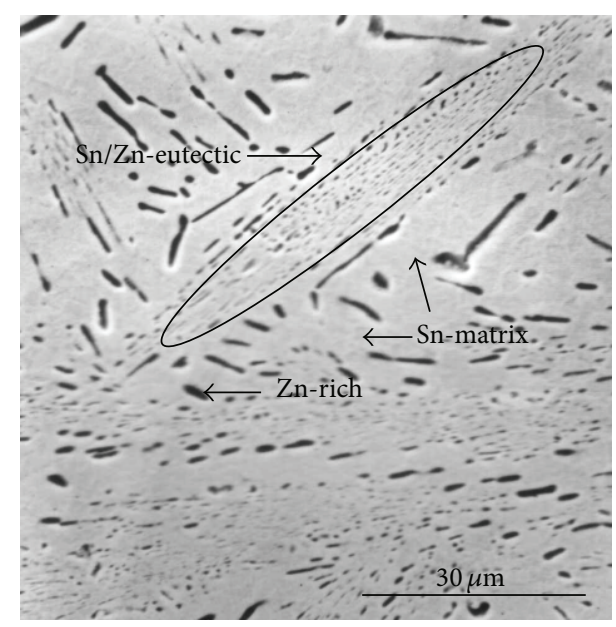

(e)

FIGURE 4: The SEM micrographs of the (a) Sn-9Zn, (b) Sn-9Zn-0.25Ga, (c) Sn-9Zn-0.50Ga, (d) Sn-9Zn-0.75Ga, and (e) Sn-9Zn-1.00Ga solder alloys. 


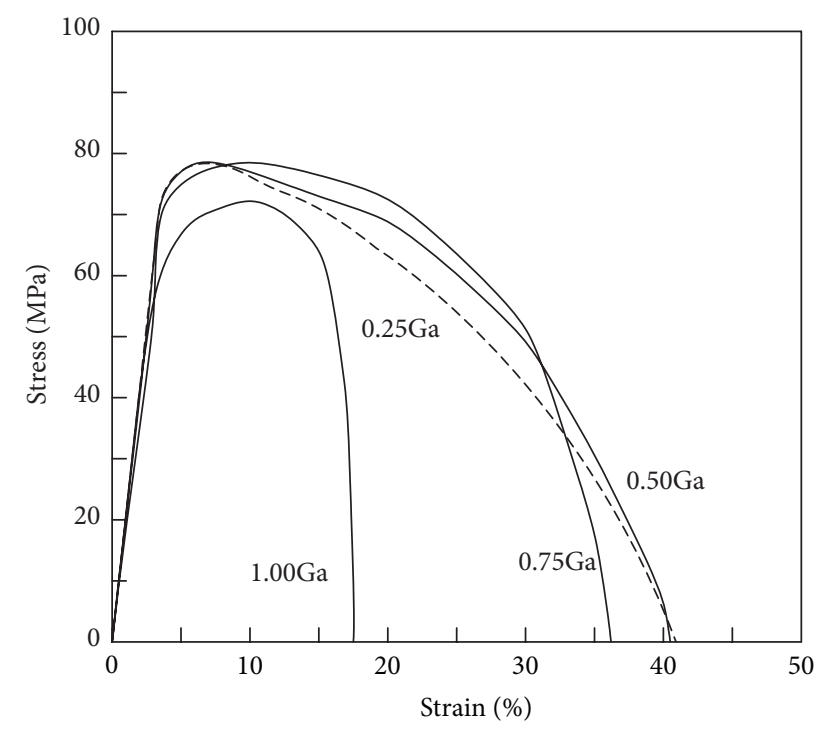

FIGURE 5: The tensile stress-strain curves of the Sn-9Zn, Sn-9Zn0.25Ga, Sn-9Zn-0.50Ga, Sn-9Zn-0.75Ga, and Sn-9Zn-1.00Ga solder alloys.

when $0.25-0.5 \mathrm{wt} . \% \mathrm{Ga}$ is added, the Sn-matrix areas slightly increase and the Zn-rich areas become slightly coarser, but the overall microstructures are very similar to those of the Sn-9Zn alloy. The solder containing $1.00 \mathrm{wt} . \% \mathrm{Ga}$ exhibits coarser nonuniform microstructures which contain large and long needle-like $\mathrm{Zn}$-rich precipitates. The cooling reaction at $250^{\circ} \mathrm{C}$ is L (liquid) $\rightarrow$ primary Sn + eutectic (Sn-Zn). This result is consistent with the $\mathrm{XRD}$ results. The phase diagram of $\mathrm{Sn}-\mathrm{Zn}$ shows a typical eutectic phase diagram with no intermetallic compounds and a limited solubility of the two elements in each phase.

Due to the addition of the $\mathrm{Ga}$ element, the $\mathrm{Zn}$-rich phase precipitates grow and disperse in the $\beta$-Sn matrix, which can be observed in Figures 4(d) and 4(e). In addition, by increasing the content of the Ga element, the fraction of the $\mathrm{Sn} / \mathrm{Zn}$ eutectic region decreases, the Sn-matrix region increases, and the needle-like $\mathrm{Zn}$-rich phase becomes coarser and longer.

3.4. Mechanical Properties. The effect of the addition of $\mathrm{Ga}$ to the mechanical properties can be seen from the stress-strain curves shown in Figure 5. The ultimate tensile strength (UTS) of the Sn-9Zn, Sn-9Zn-0.25Ga, Sn-9Zn$0.50 \mathrm{Ga}$, Sn-9Zn-0.75Ga, and Sn-9Zn-1.00Ga solder alloys is $78.1 \mathrm{MPa}, 78.4 \mathrm{MPa}, 78.3 \mathrm{MPa}, 78.5 \mathrm{MPa}$, and $72.2 \mathrm{MPa}$, respectively. The elongation failure of the Sn-9Zn, Sn-9Zn$0.25 \mathrm{Ga}$, Sn-9Zn-0.50Ga, Sn-9Zn-0.75Ga, and Sn-9Zn-1.00Ga solder alloys is $41.5 \%, 41.0 \%, 40.5 \%, 36.2 \%$, and $17.5 \%$, respectively. That is, with the addition of $0.25-0.50 \mathrm{wt} . \% \mathrm{Ga}$ to Sn-9Zn alloy, the UTS and elongation appear not to have been changed. The Sn-9Zn, Sn-9Zn-0.25Ga, and Sn-9Zn-0.5Ga alloys exhibit proper UTS and elongation behavior because of uniform microstructures. However, when the addition is increased to $1.00 \mathrm{wt} . \%$, the alloy displays an appreciable

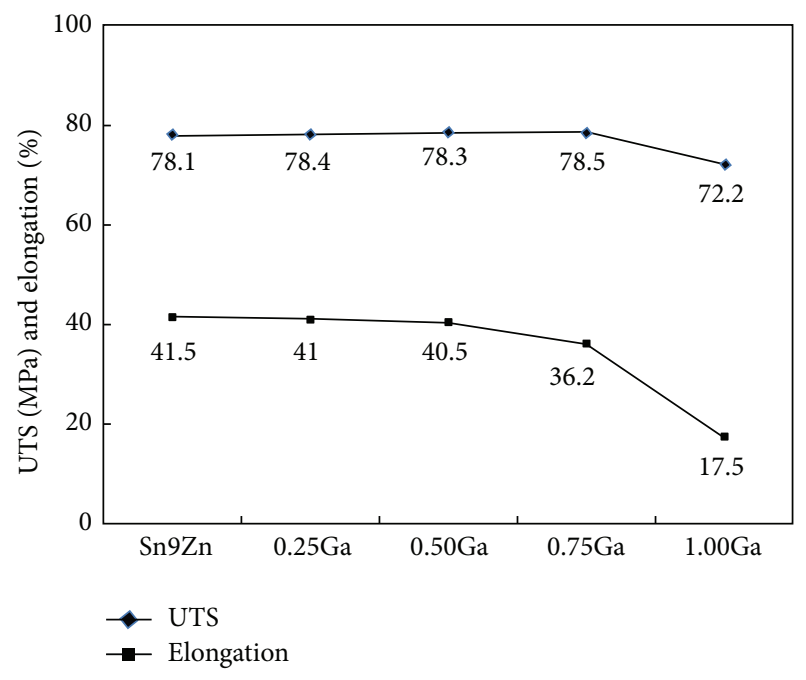

FIGURE 6: The tensile UTS and elongation of the Sn-9Zn- $x$ Ga alloys as a function of $\mathrm{Ga}$ concentration.

change in mechanical properties. The strength and ductility of the $1.00 \mathrm{wt} . \% \mathrm{Ga}$ alloy are greatly reduced. This is probably due to the coarser nonuniform microstructures with larger and longer needle-like Zn-rich precipitates in the alloy. The 1.0 wt.\% Ga addition to the Sn-9Zn alloy shown in Figure 4(e) destroys the uniform eutectic structure and needlelike precipitate of the $\mathrm{Zn}$-rich phase, and the hypoeutectic $\beta$-Sn matrix. This alloy exhibits a more coarser nonuniform microstructure. The $\beta$-Sn matrix and the $\mathrm{Zn}$-rich phase are coarser than those of the Sn-9Zn alloy. The Sn-Zn eutectic regions, with fine dispersion of Zn-rich precipitates, are stronger than the $\beta$-Sn matrix. This type of microstructure may profoundly degrade the mechanical properties of the alloy. The degradation in the mechanical property is due to the nonuniform distribution of the hard $\mathrm{Sn}-\mathrm{Zn}$ eutectic regions, leading to a preferred crack growth at the softer $\beta$ Sn matrix regions.

The tensile strength, elongation, and fracture pattern of the $\mathrm{Sn}-37 \mathrm{~Pb}$ [28] and $\mathrm{Sn}-9 \mathrm{Zn}-x \mathrm{Ga}$ solder alloys are summarized in Table 3. The Sn-9Zn-(0 0.75)Ga alloys had higher UTS and elongation, while the Sn-37Pb and Sn-9Zn1.0Ga had lower UTS and elongation.

The tensile stress and strain of the Sn-9Zn- $x \mathrm{Ga}$ alloys are shown as functions of the Ga concentration in Figure 6. It is clearly seen that if the Ga concentration is not beyond $0.50 \mathrm{wt} . \%$, the ultimate tensile strength and elongation are fixed at the same values of $78 \mathrm{MPa}$ and $41 \%$, respectively. With the addition of $1.0 \mathrm{wt} . \% \mathrm{Ga}$, the UTS and elongation of the alloy are decreased to approximately $72.2 \mathrm{MPa}$ and $17.5 \%$, respectively, which means that there is an $8 \%$ and a $57 \%$ drop in the UTS and elongation, respectively, as compared to the 0.25 wt. \% Ga alloy.

The addition of $1.0 \mathrm{Ga}$ into the Sn-9Zn alloy diminishes the eutectic structure and $\beta$-Sn matrix (Figure 4(e)). It is accompanied by a coarsening of microstructure matrix. Thus, the UTS drops from $78.1 \mathrm{MPa}$ in the $\mathrm{Sn}-9 \mathrm{Zn}$ to $72.2 \mathrm{MPa}$ in the Sn-9Zn-1.00Ga alloy. The large decrease in UTS 
TABLE 3: The mechanical properties of the $\mathrm{Sn}-37 \mathrm{~Pb}$ and $\mathrm{Sn}-9 \mathrm{Zn}-x \mathrm{Ga}$ solder alloys.

\begin{tabular}{lcccc}
\hline Solder alloys & Tensile strength $(\mathrm{MPa})$ & Elongation $(\%)$ & Fracture pattern & Reference \\
\hline $\mathrm{Sn}-37 \mathrm{~Pb}$ & 55.0 & 37.5 & Dimple & Dimple \\
$\mathrm{Sn}-9 \mathrm{Zn}$ & 78.1 & 41.5 & Dimple & This study \\
$\mathrm{Sn}-9 \mathrm{Zn}-0.25 \mathrm{Ga}$ & 78.4 & 41.0 & Dimple & This study \\
$\mathrm{Sn}-9 \mathrm{Zn}-0.50 \mathrm{Ga}$ & 78.3 & 40.5 & Dimple & This study \\
$\mathrm{Sn}-9 \mathrm{Zn}-0.75 \mathrm{Ga}$ & 78.5 & 36.2 & This study \\
$\mathrm{Sn}-9 \mathrm{Zn}-1.00 \mathrm{Ga}$ & 72.2 & 17.5 & Cleavage + dimple & This study \\
\hline
\end{tabular}

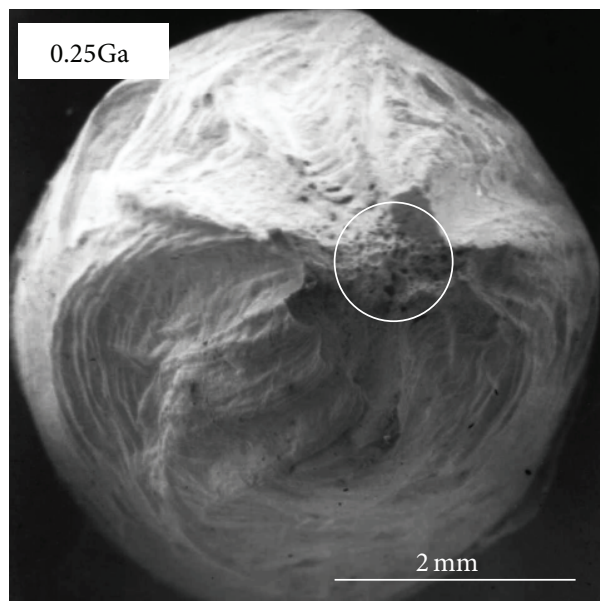

(a)

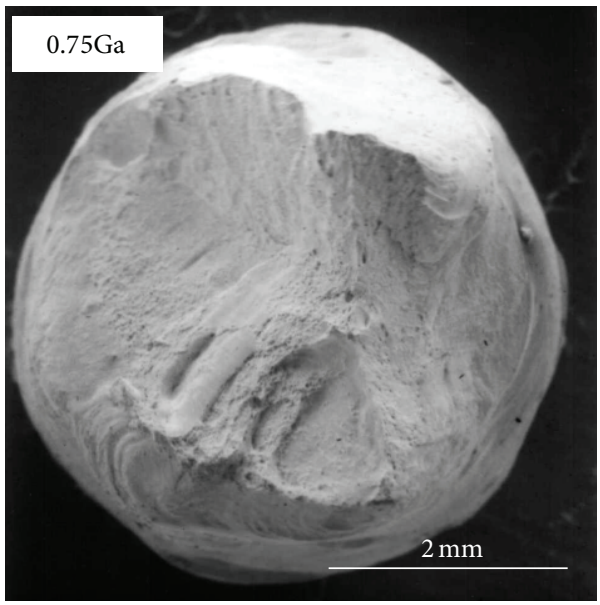

(c)

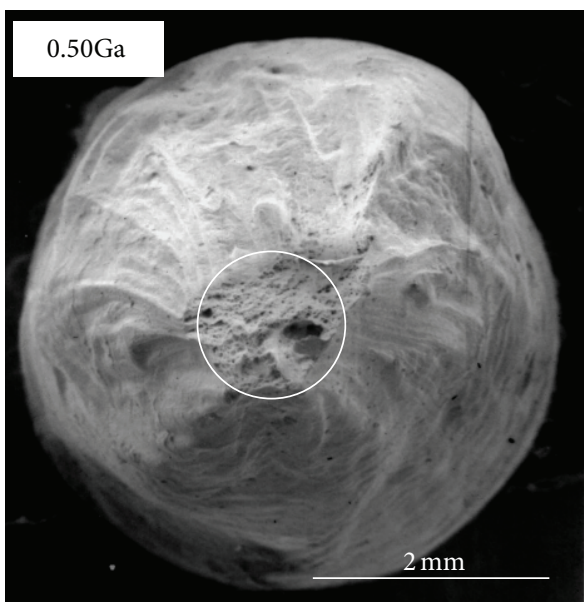

(b)

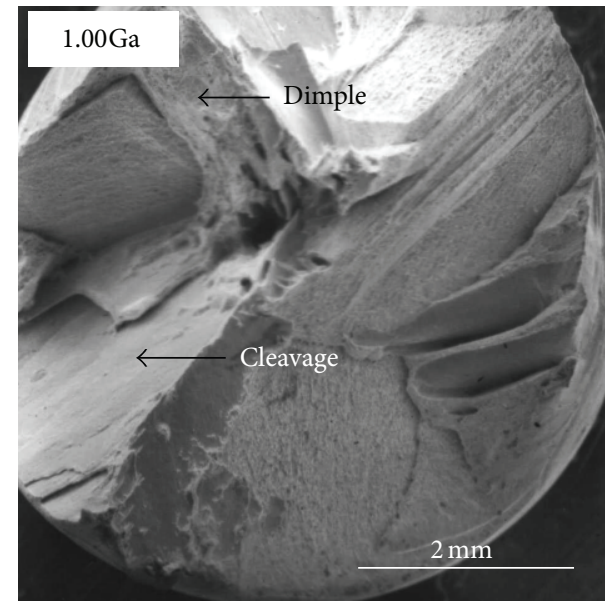

(d)

Figure 7: The fracture surfaces of the Sn-9Zn-0.25Ga, Sn-9Zn-0.50Ga, Sn-9Zn-0.75Ga, and Sn-9Zn-1.00Ga solder alloys.

caused by $1.0 \mathrm{Ga}$ additions to the $\mathrm{Sn}-9 \mathrm{Zn}$ alloy is due to a fraction of the $\mathrm{Sn} / \mathrm{Zn}$ eutectic region decreasing, the Snmatrix region increasing, and the needle-like $\mathrm{Zn}$-rich phase becoming coarser and longer. The Ga-Zn phase diagram [31] shows that hexagonal $(\mathrm{Zn})$ solid solution possesses a maximum solubility of 2.36 at. $\% \mathrm{Ga}$ at $260^{\circ} \mathrm{C}$. Meanwhile, Sn exhibits [32] a maximum solubility of 7.1 at.\% Ga. Thus, most of the $\mathrm{Ga}$ is dissolved in the $\mathrm{Sn}$-rich and $\mathrm{Zn}$-rich phases. The atomic radii of tin, zinc, and gallium have nearly the same size. Thus, when $\mathrm{Ga}$ is added to the Sn-9Zn alloy, it may form a solid solution structure. It is believed that strengthening effect of the $\mathrm{Ga}$ addition is attributed to the dissolution of $\mathrm{Ga}$ in Sn. However, the strengthening effect of the $\mathrm{Ga}$ is not improved by increasing Ga content, as the Ga element has a small atom size. This contributes to the formation of the needle-like precipitate of the $\mathrm{Zn}$ rich phases and the hypoeutectic $\beta$-Sn matrix, while the eutectic cell boundary becomes prominent in the matrix. The tensile strain is obviously decreased because stress concentration occurs at the interface between either the hard $\mathrm{Zn}$-rich phases or the $\mathrm{Sn}-\mathrm{Zn}$ eutectic regions and the $\beta$-Sn matrix. 


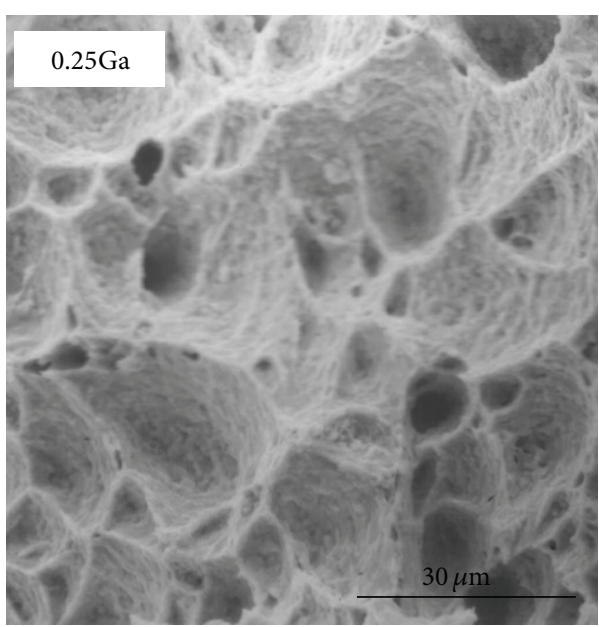

(a)

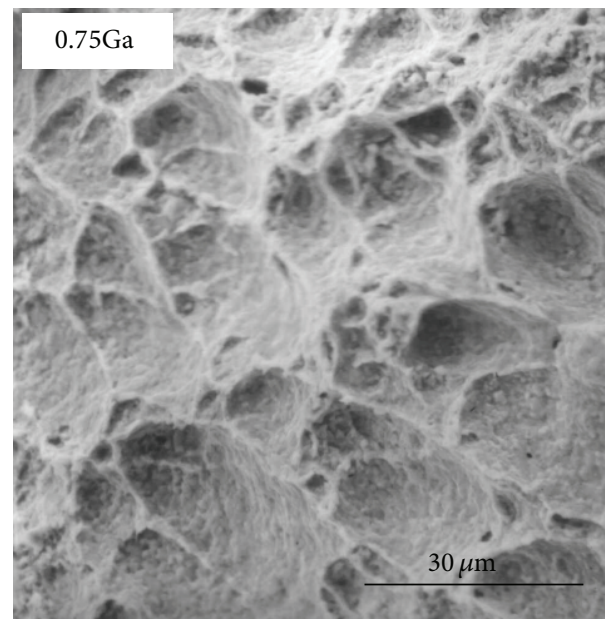

(c)

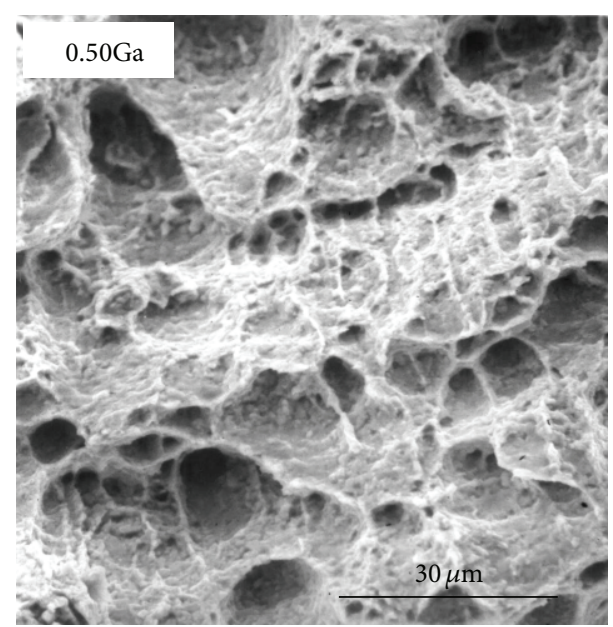

(b)

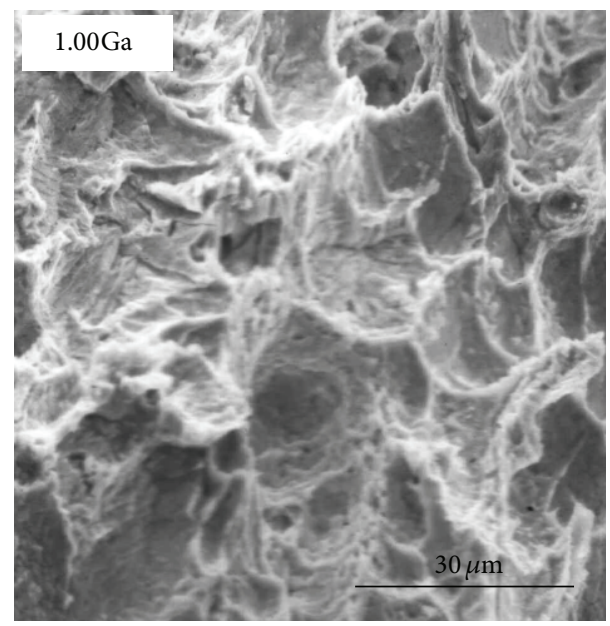

(d)

Figure 8: A higher magnification of the fracture surfaces of Sn-9Zn-0.25Ga, Sn-9Zn-0.50Ga, Sn-9Zn-0.75Ga and Sn-9Zn-1.00Ga solder alloys.

3.5. Fracture Morphology. Figure 7 shows the scanning electron microscopy (SEM) of the fracture surfaces of four of the tensile specimens made from Sn-9Zn-0.25Ga, Sn-9Zn0.50Ga, Sn-9Zn-0.75Ga, and Sn-9Zn-1.00Ga solder alloys. A higher magnification of the fracture surfaces of the four alloys is provided in Figure 8. It was found that an additional $0.25-0.50$ wt.\% small-sized cup and cone fracture, which is referred to as a near-complete ductile fracture, is observed within. With the addition of a $0.75 \mathrm{wt} . \%$, the size of the cup and cone fracture becomes larger. The fracture surface of the 1.00 wt.\% Ga alloy displays partial cleavage and a partially dimpled fracture, which are indicated by the circles in Figure 7 . This indicates a reduction in the ductility of the alloy taking place at $1.00 \mathrm{wt} . \% \mathrm{Ga}$, which is due to the formation of larger and longer needle $\mathrm{Zn}$-rich precipitates and of the coarser and nonuniform microstructures. According to the work of Kim et al. [9], the fractures of the Sn- $8 \mathrm{Zn}-6 \mathrm{Bi}$ and $\mathrm{Sn}-8 \mathrm{Zn}-8 \mathrm{Bi}$ alloys show a typical brittle-fracture pattern and fractures occur along the coarse dendrite or long $\mathrm{Zn}$ precipitates.

\section{Conclusions}

The present study is concerned with the effects of a gallium addition on microstructures and thermal and mechanical properties of Sn-9Zn solder alloys. The results show that the melting temperatures of the alloys decrease with an increase in $\mathrm{Ga}$ concentration, while the pasty ranges of the alloys are simultaneously enlarged. The experimental results also show that the addition of the Ga element causes the $\mathrm{Zn}$-rich phase precipitates to grow and disperse in the $\beta$-Sn matrix. In addition, by increasing the content of the Ga element, the fraction of the $\mathrm{Sn} / \mathrm{Zn}$ eutectic region decreases, the $\mathrm{Sn}$-matrix region increases, and the needle-like $\mathrm{Zn}$-rich phase becomes coarser and longer. However, the overall microstructure is still very similar to that of the $\mathrm{Sn}-9 \mathrm{Zn}$ alloy. Meanwhile, small additions of $0 \sim 0.75 \mathrm{wt} . \% \mathrm{Ga}$ decrease the melting point of the $\mathrm{Sn}-9 \mathrm{Zn}-x \mathrm{Ga}$ solders while maintaining the same strength and ductility as the Sn-9Zn solder; one also observes small cup and cone fractures on the fracture surfaces which exhibit near-complete ductile fractures. As the addition is increased 
to $0.75 \mathrm{wt} . \%$, larger cup and cone fractures are seen. The 1.00 wt.\% Ga alloy has a lower strength and ductility due to the coarser and nonuniform microstructures. However, the fracture surfaces of the $1.00 \mathrm{wt}$. $\%$ Ga alloy show only a partially cleaved and partially dimpled fracture.

\section{Conflict of Interests}

The authors declare that there is no conflict of interests regarding the publication of this paper.

\section{Acknowledgment}

The authors acknowledge the financial support provided by the National Science Council of the Republic of China.

\section{References}

[1] M. McCormack and S. Jin, "Progress in the design of new lead-free solder alloys," The Journal of the Minerals, Metals \& Materials Society, vol. 45, no. 7, pp. 36-40, 1993.

[2] M. Abtew and G. Selvaduray, "Lead-free solders in microelectronics," Materials Science and Engineering R, vol. 27, no. 5, pp. 95-141, 2000.

[3] H. Mavoori, J. Chin, S. Vaynman, B. Moran, L. Keer, and M. Fine, "Creep, stress relaxation, and plastic deformation in SnAg and Sn-Zn eutectic solders," Journal of Electronic Materials, vol. 26, no. 7, pp. 783-790, 1997.

[4] K. Suganuma, T. Murata, H. Noguchi, and Y. Toyoda, "Heat resistance of $\mathrm{Sn}-9 \mathrm{Zn}$ solder/Cu interface with or without coating," Journal of Materials Research, vol. 15, no. 4, pp. 884-891, 2000.

[5] E. P. Wood and K. L. Nimmo, "In search of new lead-free electronic solders," Journal of Electronic Materials, vol. 23, no. 8, pp. 709-713, 1994.

[6] K. Suganuma, K. Niihara, T. Shoutoku, and Y. Nakamura, "Wetting and interface microstructure between $\mathrm{Sn}-\mathrm{Zn}$ binary alloys and Cu," Journal of Materials Research, vol. 13, no. 10, pp. 28592865, 1998.

[7] M. McCormack and S. Jin, "New, lead-free solders," Journal of Electronic Materials, vol. 23, no. 7, pp. 635-640, 1994.

[8] K. Chen, S. Cheng, S. Wu, and K. Lin, "Effects of small additions of $\mathrm{Ag}, \mathrm{Al}$, and $\mathrm{Ga}$ on the structure and properties of the $\mathrm{Sn}-9 \mathrm{Zn}$ eutectic alloy," Journal of Alloys and Compounds, vol. 416, no. 1-2, pp. 98-105, 2006.

[9] Y. Kim, K. Kim, C. Hwang, and K. Suganuma, "Effect of composition and cooling rate on microstructure and tensile properties of Sn-Zn-Bi alloys," Journal of Alloys and Compounds, vol. 352, no. 1-2, pp. 237-245, 2003.

[10] M. Date, K. N. Tu, T. Shoji, M. Fujiyoshi, and K. Sato, "Interfacial reactions and impact reliability of $\mathrm{Sn}-\mathrm{Zn}$ solder joints on $\mathrm{Cu}$ or electroless $\mathrm{Au} / \mathrm{Ni}(\mathrm{P})$ bond-pads," Journal of Materials Research, vol. 19, no. 10, pp. 2887-2896, 2004.

[11] A. Hirose, H. Yanagawa, E. Ide, and K. F. Kobayashi, "Joint strength and interfacial microstructure between $\mathrm{Sn}-\mathrm{Ag}-\mathrm{Cu}$ and Sn-Zn-Bi solders and Cu substrate," Science and Technology of Advanced Materials, vol. 5, no. 1-2, pp. 267-276, 2004.
[12] A. A. El-Daly, Y. Swilem, M. H. Makled, M. G. El-Shaarawy, and A. M. Abdraboh, "Thermal and mechanical properties of SnZn-Bi lead-free solder alloys," Journal of Alloys and Compounds, vol. 484, no. 1-2, pp. 134-142, 2009.

[13] S. Wang, T. Chin, C. Yang, S. Chen, and C. Chuang, "Pbfree solder-alloy based on $\mathrm{Sn}-\mathrm{Zn}$-Bi with the addition of germanium," Journal of Alloys and Compounds, vol. 497, no. 1-2, pp. 428-431, 2010.

[14] K. Lin, L. Wen, and T. Liu, "The microstructures of the Sn-ZnAl solder alloys," Journal of Electronic Materials, vol. 27, no. 3, pp. 97-105, 1998.

[15] K. Lin and Y. Wang, "Wetting interaction of Pb-free Sn-ZnAl solders on metal plated substrate," Journal of Electronic Materials, vol. 27, no. 11, pp. 1205-1210, 1998.

[16] K. Lin and L. Wen, "The wetting of copper by Al-Zn-Sn solders," Journal of Materials Science, vol. 9, no. 1, pp. 5-8, 1998.

[17] K. Lin and T. Liu, "High-temperature oxidation of a Sn-Zn-Al solder," Oxidation of Metals, vol. 50, no. 3-4, pp. 255-267, 1998.

[18] K. Lin and T. Liu, "The electrochemical corrosion behaviour of $\mathrm{Pb}$-free $\mathrm{Al}-\mathrm{Zn}$ - $\mathrm{Sn}$ solders in $\mathrm{NaCl}$ solution," Materials Chemistry and Physics, vol. 56, no. 2, pp. 171-176, 1998.

[19] K. Lin and C. Shih, "Wetting interaction between Sn-Zn-Ag solders and Cu," Journal of Electronic Materials, vol. 32, no. 2, pp. 95-100, 2003.

[20] J. M. Song, G. F. Lan, T. S. Lui, and L. H. Chen, "Microstructure and tensile properties of Sn-9Zn-xAg lead-free solder alloys," Scripta Materialia, vol. 48, no. 8, pp. 1047-1051, 2003.

[21] J. M. Song, T. S. Lui, G. F. Lan, and L. H. Chen, "Resonant vibration behavior of Sn-Zn-Ag solder alloys," Journal of Alloys and Compounds, vol. 379, no. 1-2, pp. 233-239, 2004.

[22] G. Saad, A. Fawzy, and E. Shawky, "Effect of Ag addition on the creep characteristics of Sn-8.8 wt\%Zn solder alloy," Journal of Alloys and Compounds, vol. 479, no. 1-2, pp. 844-850, 2009.

[23] X. Chen, A. Hu, M. Li, and D. Mao, "Study on the properties of Sn-9Zn- $x$ Cr lead-free solder," Journal of Alloys and Compounds, vol. 460, no. 1-2, pp. 478-484, 2008.

[24] J. Lee, K. Kim, M. Inoue, J. Jiang, and K. Suganuma, "Effects of $\mathrm{Ag}$ and $\mathrm{Cu}$ addition on microstructural properties and oxidation resistance of $\mathrm{Sn}-\mathrm{Zn}$ eutectic alloy," Journal of Alloys and Compounds, vol. 454, no. 1-2, pp. 310-320, 2008.

[25] C. M. L. Wu, D. Q. Yu, C. M. T. Law, and L. Wang, “The properties of Sn-9Zn lead-free solder alloys doped with trace rare earth elements," Journal of Electronic Materials, vol. 31, no. 9, pp. 921927, 2002.

[26] C. M. L. Wu, C. M. T. Law, D. Q. Yu, and L. Wang, "The wettability and microstructure of Sn-Zn-RE alloys," Journal of Electronic Materials, vol. 32, no. 2, pp. 63-69, 2003.

[27] C. M. L. Wu, D. Q. Yu, C. M. T. Law, and L. Wang, "Properties of lead-free solder alloys with rare earth element additions," Materials Science and Engineering $R$, vol. 44, no. 1, pp. 1-44, 2004.

[28] K. Chen and K. Lin, "The microstructures and mechanical properties of the Sn-Zn-Ag-Al-Ga solder alloys-the effect of Ag," Journal of Electronic Materials, vol. 31, no. 8, pp. 861-867, 2002.

[29] M. Hansen, Constitution of Binary Alloys, McGraw-Hill Book, New York, NY, USA, 2nd edition, 1958. 
[30] S. K. Bhattacharya and D. F. Baldwin, "Gallium alloy breakthrough for via-filling application," Advanced Packaging, vol. 9, no. 8, pp. 61-64, 2000.

[31] J. Dutkiewicz, Z. Moser, L. Zabdyr et al., "The Ga-Zn (galliumzinc) system," Bulletin of Alloy Phase Diagrams, vol. 11, no. 1, pp. 77-82, 1990.

[32] T. J. Anderson and I. Ansara, "The Ga-Sn (gallium-tin) system," Journal of Phase Equilibria, vol. 13, no. 2, pp. 181-189, 1992.

[33] A. A. El-Daly, Y. Swilem, and A. E. Hammad, "Creep properties of Sn-Sb based lead-free solder alloys," Journal of Alloys and Compounds, vol. 471, no. 1-2, pp. 98-104, 2009. 

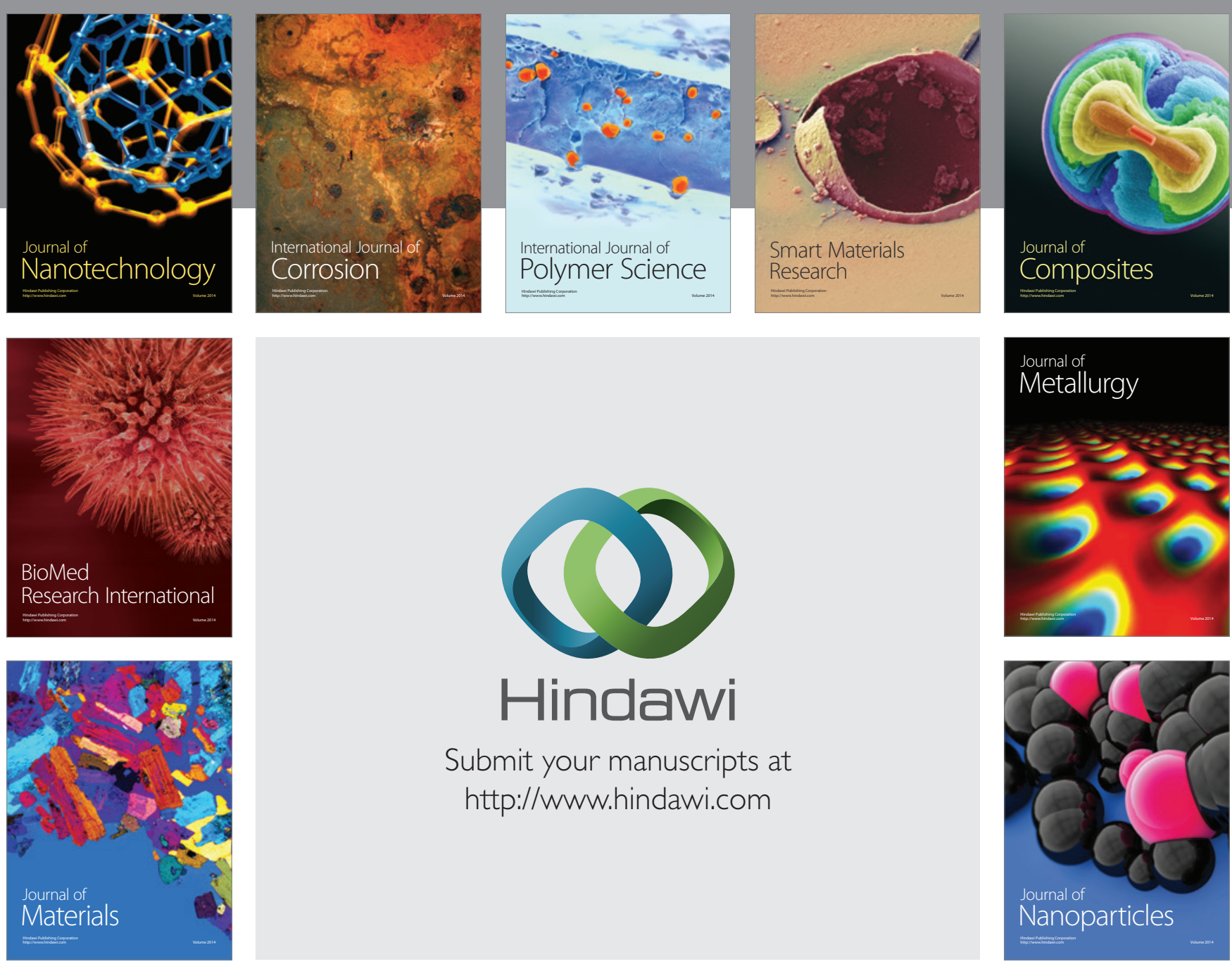

Submit your manuscripts at http://www.hindawi.com
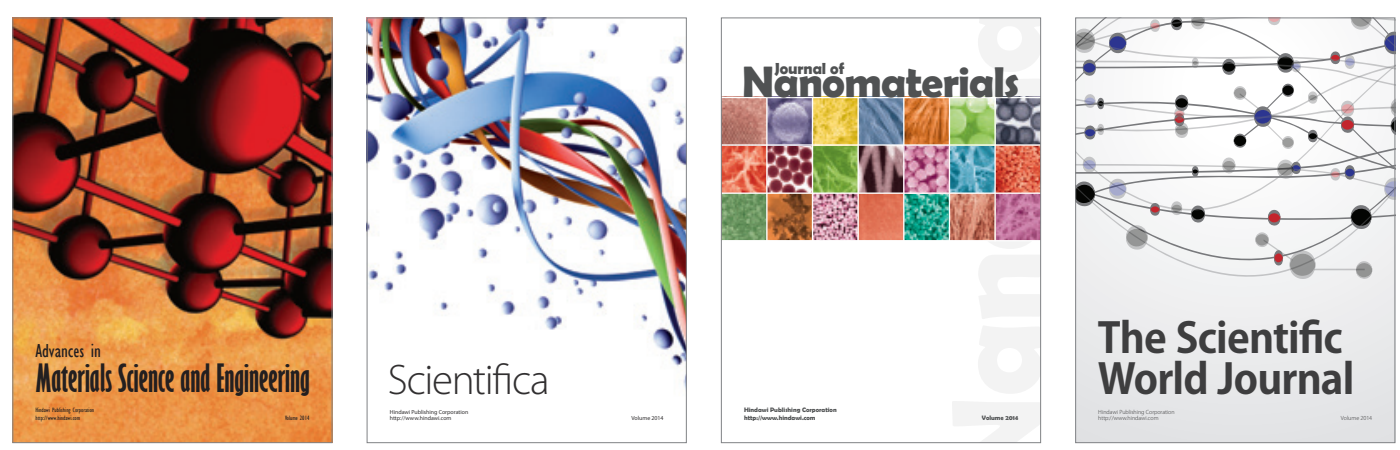

\section{The Scientific World Journal}
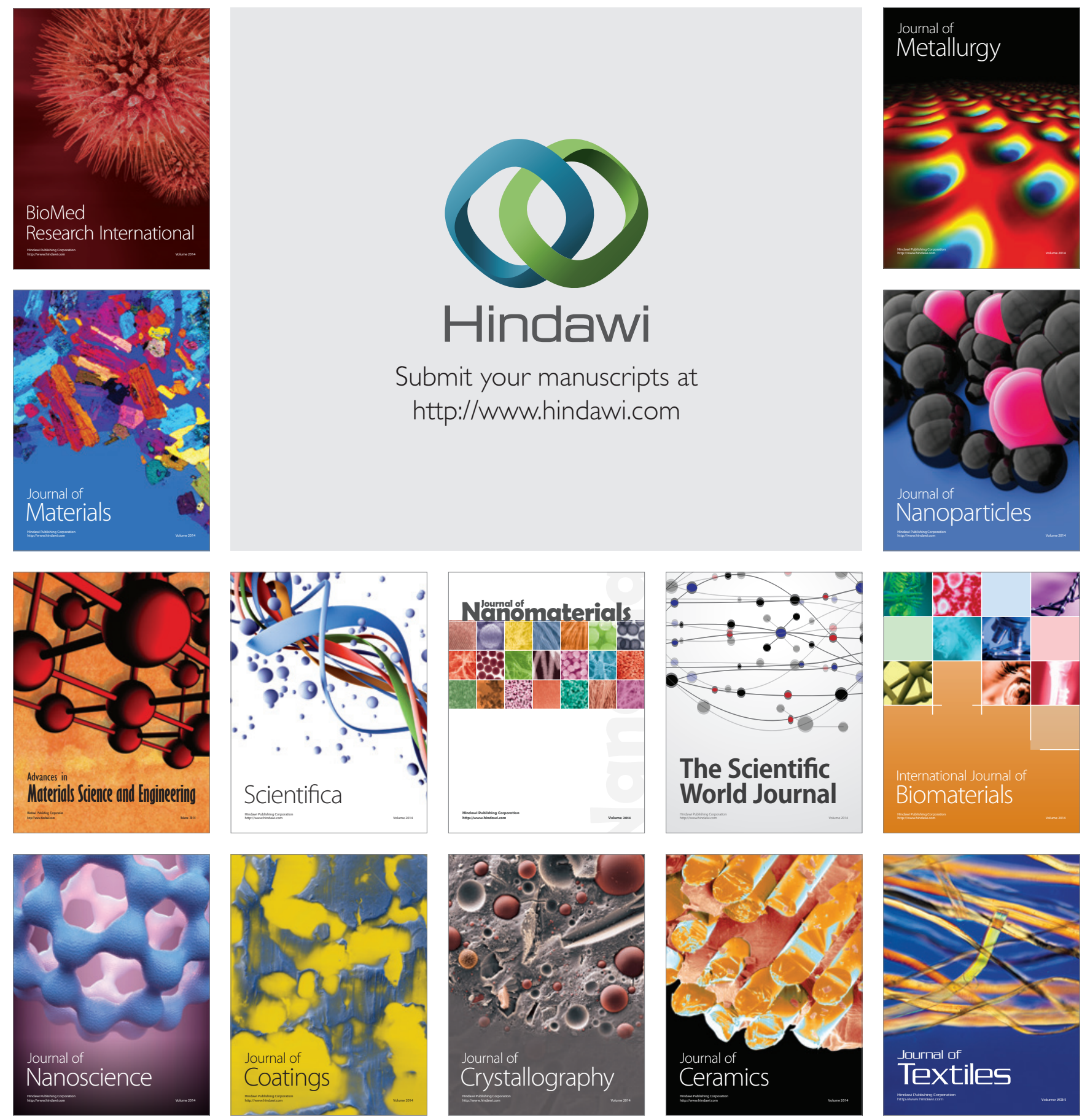